\title{
Supplier selection using Fuzzy AHP and Fuzzy Vikor for XYZ Pharmaceutical Manufacturing Company
}

\author{
Ahmad Fakhry Nadar ${ }^{1}$, Ruzanita Mat Rani ${ }^{2 *}$ \\ ${ }^{1,2}$ Centre of Statistical and Decision Sciences Studies, Faculty of Computer and Mathematical \\ Sciences, Universiti Teknologi MARA, 40450 Shah Alam, Selangor, Malaysia. \\ *Corresponding author: ruzanita@tmsk.uitm.edu.my
}

DOI: https://doi.org/10.37134/ejsmt.vol7.1.2.2020

Received: 13 May 2019; Accepted: 01 February 2020; Published: 03 February 2020

\begin{abstract}
Supplier selection is not an easy process as it typically involves multiple criteria and it requires human judgment. Therefore, there is a need to have a better system for supplier selection due to uncertainty and vagueness that exist in dealing with the multiple criteria decision making $(\mathrm{MCDM})$ problem. This study is aimed to identify the important criteria for the selection of the best pharmaceutical raw materials supplier for XYZ Pharmaceutical Manufacturing company by using Fuzzy Analytical Hierarchy Process (AHP) and Fuzzy VIKOR approaches. Furthermore, this paper also presents the comparison results between the two methods in determining the best supplier. Fuzzy theory was used since it provides a right tool to encounter the uncertainties and complexity of decision making environment. This study investigated eight alternative suppliers based on seven criteria evaluated by two decision makers from the company. This study has successfully identified the top three most important criteria for the selection of supplier, namely, Regulatory Compliance, Price, and Product Variety. This study highlighted that Regulatory Compliance is a new important criterion for the pharmaceutical company to consider in future supplier selection. Based on the alternative results of Fuzzy AHP, it was found that the top three most important supplier were $A_{5}, A_{3}$ and $A_{1}$. While based on the alternative results of Fuzzy VIKOR, it showed that the top three most important supplier were $A_{5}, A_{3}$ and $A_{7}$. The comparison results between the two methods have shown that the Fuzzy VIKOR method is more suited to the problem of supplier selection.
\end{abstract}

Keywords: supplier selection; Fuzzy AHP; Fuzzy Vikor

\section{INTRODUCTION}

Decision of supplier selection is an essential segment of production and logistics management for many organizations. The decision of supplier selection involves the selection of individual suppliers to utilize and the assurance of request amounts to be put with the selected suppliers. According to [1], selecting right suppliers would fundamentally decrease the cost of material and it helps to enhance corporate aggressiveness of which numerous specialists trust that supplier selection is the most essential decision for the association.

This article focuses on the factors that influence the process of decision making in the selection of suppliers for the pharmaceutical company. From the aspect of psychology, manufacturers emphasize their satisfaction in terms of supplier selection [2]. One of the selection process is to find the right suppliers by comparing their criteria in order to make a decision. The most important and challenging activity to the company is the supplier selection. In the pharmaceutical company, selecting the right supplier is a very complicated task. The decision for selecting the right supplier may expose to errors [3]. According to [4], the right supplier will lead to the satisfaction of the company's requirements and the long-term connection. On the other hand, the right supplier will also help to rise the financial steadiness in the market [5]. 
Most of pharmaceutical companies nowadays do not realize the problems arising from dealing with suppliers. Among the complaints received by the manufacturer are as follows; the product purchased is not acceptable, the products are not registered with National Pharmaceutical Regulatory Agency (NPRA), the supplier has weak financial background, the product received is defective or in less satisfactory condition, the quality of product is low, the product is not delivered within the agreed time and the product received is not the product ordered and it is difficult to return the damaged items. All these problems may result in significant loss to the manufacturers. Therefore, this article would assist the pharmaceutical company to select the right supplier by using Multiple-Criteria Decision Making (MCDM) method in order to overcome these problems.

When selecting the best supplier in the pharmaceutical industry, [6] were using the method of Fuzzy AHP (Analytical Hierarchy Process) to choose the best supplier of maize starch for a pharmaceutical company in Iran based on five criteria, namely price, quality, service, organization and technical. This method was successfully implemented in the pairwise comparison matrices with the help of the expert's inputs. On the other hand, there is a new approach to obtain the rankings, namely Fuzzy VIKOR. [7] emphasized the use of this method which concentrates on ranking and choosing from a set of alternatives. Moreover, they decided to compromise solutions for a problem with contradictory criteria.

\section{METHODOLOGY}

\section{A. Selection of criteria}

Currently, XYZ Pharmaceutical Manufacturing company is selecting the supplier of pharmaceutical raw material based on three criteria, namely price, quality and service. This article, however, proposes additional criteria in order to improve the selection process of XYZ Pharmaceutical Manufacturing company, namely regulatory compliance [8], capacity [9], financial status [10] and product variety [11]. The description of each of the criteria are tabulated as below (Table 1):

Table 1. Description of Criteria

\begin{tabular}{ll}
\hline \multicolumn{1}{c}{ Criteria } & \multicolumn{1}{c}{ Description } \\
\hline $\mathrm{C}_{1}$ : Service & $\begin{array}{l}\text { Supplier is able to provide on-time delivery, value added services, and ease } \\
\text { of communication }\end{array}$ \\
$\mathrm{C}_{2}$ : Product Quality & $\begin{array}{l}\text { Pharmaceutical raw materials are of good quality and meet company's } \\
\text { standards. }\end{array}$ \\
$\mathrm{C}_{3}$ : Price & The price of the pharmaceutical raw materials. \\
$\mathrm{C}_{4}:$ Financial Status & The supplier has a strong financial status. \\
$\mathrm{C}_{5}:$ Product Variety & Type of different pharmaceutical raw materials that can be supplied. \\
$\mathrm{C}_{6}:$ Capacity & Supplier is able to supply the quantity required. \\
$\mathrm{C}_{7}:$ Regulatory Compliance & Every pharmaceutical raw materials distributed must be registered under \\
\hline
\end{tabular}

\section{B. Data Collection}

Primary data was obtained by using a set of questionnaire. The respondents were the two decision makers from the Supply Chain Management Department, namely the Head of Quality and the Head of Plant. Before the survey was conducted, a pilot study was conducted where unstructured interviews were conducted with five manufacturing managers from different industrial sectors. During the interview sessions, the managers were asked based on the questionnaire in order to identify phrases in each section of the questionnaire which 
EDUCATUM JSMT Vol. 7 No.1 (2020)

ISSN 2289-7070 / eISSN 2462-2451 (14-21)

https://ejournal.upsi.edu.my/index.php/EJSMT/index

are vague or difficult to understand phrases. The pilot study was conducted in order to ensure that the managers have no problem in understanding and answering the questions.

\section{Model Development}

\section{Fuzzy AHP}

According to [12] the method of Ayhan's analysis, his introduced the applications of the extent analysis method for the synthetic extent values of the pairwise comparisons on Fuzzy AHP. Triangular fuzzy numbers are used in the pairwise comparison matrix. There are five steps for Fuzzy AHP. The steps are as follows:

Step 1: The pair wise contribution matric is shown in Eq. 1, where $\tilde{a}_{i j}^{k}$ indicates the $k^{\text {th }}$ decision maker's preference of $i^{\text {th }}$ criterion over $j^{\text {th }}$ criterion, via fuzzy triangular numbers.

$$
\tilde{A}^{k}=\left[\begin{array}{cccc}
\tilde{a}_{11}^{k} & \tilde{a}_{12}^{k} & \ldots & \tilde{a}_{1 n}^{k} \\
\tilde{a}_{21}^{k} & \ldots & \ldots & \tilde{a}_{1 n}^{k} \\
\ldots & \ldots & \ldots & \ldots \\
\tilde{a}_{n}^{k} & \tilde{a}_{n 1}^{k} & \ldots & \tilde{a}_{n n}^{k}
\end{array}\right]
$$

Step 2: If there is more than one decision maker, preferences of each decision maker $\tilde{a}_{i j}^{k}$ are averaged by using geometric mean techniques and $\tilde{a}_{i j}$ is calculated as shown in Eq. 2.

$$
\tilde{a}_{i j}=\left(\tilde{a}_{i j}^{1} \otimes \tilde{a}_{i j}^{2} \otimes \ldots \tilde{a}_{i j}^{k}\right) \frac{1}{k}, i=1,2, \ldots, n, j=1,2, \ldots, n k=1,2, \ldots, n
$$

Step 3: According to fuzzy geometric mean, pair-wise contribution matric is updated as shown in Eq. 3.

$$
\tilde{A}=\left[\begin{array}{ccc}
\tilde{a}_{11} & \cdots & \tilde{a}_{1 n} \\
\vdots & \ddots & \vdots \\
\tilde{a}_{n 1} & \cdots & \tilde{a}_{i j}
\end{array}\right]
$$

Step 4: Find the priority of each criterion by incorporating next four sub-steps.

Step 4a: Compare the geometric mean of fuzzy with the values of each criterion. Then calculate the values as shown in Eq. 4 where $\widetilde{r}_{l}$ represents triangular values.

$$
\tilde{r}_{i}=\left(\prod_{j=1}^{n} a_{i j}\right)^{\frac{1}{n}}=\left(\tilde{a}_{i 1} \oplus \tilde{a}_{i 2} \oplus \ldots \tilde{a}_{i n}\right)^{\frac{1}{n}}, i=1,2, \ldots, n
$$


Step 4b: To find the fuzzy weight of criterion $i,\left(\widetilde{W}_{i}\right)$ multiply each $\widetilde{r}_{l}$ with this reverse vector. Refer to Eq. 5 .

$$
\tilde{W}_{i}=\tilde{r}_{i} \otimes\left(\tilde{r}_{1} \oplus \tilde{r}_{2} \oplus \ldots \oplus \tilde{r}_{n}\right)^{-1}, i=1,2, \ldots, n
$$

Step 4c: Compute the Best Non-Fuzzy Performance (BNP), Eq. 6 value of the fuzzy weights for each criterion.

$$
B N P_{W i}=\frac{\left(\left(U_{W i}-L_{W i}\right)+\left(M_{W i}-L_{W i}\right)\right)}{3}+L_{W i}
$$

Step 4d: Step 4c is non-fuzzy number and it needs to be normalized by using Eq. 7.

$$
B N P_{N i}=\frac{B N P_{W i}}{\sum_{i=1}^{n} B N P_{W i}}
$$

These 4 steps are performed to find the normalized weights of both criteria and alternatives. The score of each alternative is calculated by multiplying the weight of each alternative with the related criteria. The alternative with the highest score is recommended to the decision maker based on the results.

\section{Fuzzy VIKOR}

According to [13], this approach pursues to find the best compromise solution between decision makers to bring into line with the objectives of human thought. VIKOR algorithm based on modified fuzzy numbers are as follows:

Step 1: Compute the normalized fuzzy decision matrix. Normalized fuzzy result matrix is calculated to ensure that every criterion value is between 0 and 1 , so that all criteria are standard and comparable to each other. In this case, the VIKOR method uses linear normalization to stabilize. Linear normalization formula indicated by the score of $\tilde{R}_{i j}$ as follows, Eq. 8:

$$
\tilde{R}_{i j}=\left(\frac{\widetilde{x}_{j}-\tilde{x}_{i j}}{\widetilde{x}_{j}{ }_{j}-\widetilde{x}_{j}}\right)
$$

where $\widetilde{R}_{i j}$ is the normalized score for alternatives $i$ of the $j^{\text {th }}$ criteria. $\widetilde{x}_{i j}$ is the value of the $j^{\text {th }}$ criteria for the alternative $i$. The best value of $j^{\text {th }}$ criteria is $\widetilde{x}_{j}^{x}$ and the the worst value $\widetilde{x}_{j}^{-}$.

Step 2: Compute the utility measure of $\tilde{S}_{i}$ as shown in Eq. 9

$$
\tilde{S}_{i}=\sum_{i=1}^{n} \widetilde{w}_{j}\left(\tilde{R}_{i j}\right)
$$

where $w_{j}$ is the weight of $j^{\text {th }}$ criteria and regret measure, $\mathbf{R}_{\mathrm{i}} \max _{i}\left[\mathrm{w}_{j} \mathbf{R}_{i j}\right]$. 
EDUCATUM JSMT Vol. 7 No.1 (2020)

ISSN 2289-7070 / eISSN 2462-2451 (14-21)

https://ejournal.upsi.edu.my/index.php/EJSMT/index

Step 3: Compute the index VIKOR, $\tilde{Q}_{i}$ as given in Eq. 10.

$$
\tilde{Q}_{i}=\left(\frac{\tilde{S}_{i}-\widetilde{S}}{\widetilde{S^{+}}-\widetilde{S}}\right) v+\left(\frac{\tilde{R}_{i}-\widetilde{R}^{-}}{\widetilde{R^{+}}-\widetilde{R}^{-}}\right)(1-v)
$$

where, $\widetilde{S^{+}}=\max _{i} \tilde{S}_{i}, \widetilde{S^{-}}=\min _{i} \tilde{S}_{i}, \widetilde{R^{+}}=\max _{i} \tilde{R}_{i}$, and $\widetilde{R}^{-}=\min _{i} \tilde{R}_{i} \cdot v$ introduced as a weight in the maximum group utility strategy. From literature, it is concluded that the VIKOR index value is mostly taken as $v=0.5$.

Step 4: Sorting the value $\tilde{S}, \tilde{R}$ and $\tilde{Q}$ in ascending order. The best alternative in order of $\tilde{Q}_{i}$ is the smaller value of $\tilde{Q}_{i}$.

Step 5: The alternatives $A^{(1)}$ alternative will be proposed as the best alternative in providing a compromise solution if and only if it meets two conditions:

C1 : Acceptable advantage. The alternative $A^{(1)}$ is accepted as the best advantage when the difference index of VIKOR $\tilde{Q}$ between alternative $A^{(2)}$ and $A^{(1)}$ must be greater than or equal to the value of DQ or in other words, refer to Eq. (11).

$$
\tilde{Q}_{A^{(2)}}-\tilde{Q}_{A^{(1)}} \geq D Q \text { with } D Q=\frac{1}{M-1}
$$

C2 : Acceptable stability in decision making. Alternative $A^{(1)}$ must also be in the best ranked by .

When one of the conditions is not satisfied, a set of compromise solution will be proposed as follows:

i. If $\boldsymbol{C l}$ is not satisfied:

Then the alternative set $A^{(1)}, A^{(2)}$ and $A^{(m)}$ considered together with its best $A^{(m)}$ determined by the relationship $\tilde{Q}_{A^{(m)}}-\tilde{Q}_{A^{(1)}}<D Q$

ii. If $\boldsymbol{C} 2$ is not satisfied: Thus, both alternative $A^{(1)}$ dan $A^{(2)}$ are recommended as the best options or in other words the two alternatives can be described as the best alternative.

\section{Comparison Between Fuzzy AHP and Fuzzy VIKOR}

The comparison of both methods will be done in order to help researcher and practitioners to choose the more effective approaches of supplier selection. Therefore, Spearman's rank correlation coefficient will be used to determine the appropriate method for selection of pharmaceutical raw materials supplier.

Spearman's rank correlation coefficient measures the similarity between the two sets of rankings. This method shows the comparison of the strength of the relationship of two variables. The formula to get the value of $r$ is as follows, Eq. 12:

$$
r_{s}=1-\frac{6 \sum_{i=1}^{n} d_{i}^{2}}{n\left(n^{2}-1\right)}
$$

Where, $d_{i}$ is the difference between ranking and $\mathrm{n}$ is the sample size (supplier). 


\section{RESULT AND DISCUSSION}

Two decision makers were assigned to evaluate the criteria for selection of supplier in order to find the weightage. All calculations were carried out by using Microsoft Excel. Data obtained from the questionnaire will be used to show the implementation of Fuzzy AHP and Fuzzy VIKOR. Thereafter, the important criteria for the selection of pharmaceutical raw materials suppliers for XYZ Pharmaceutical Manufacturing company are identified.

Table 2. Normalized weight for each criterion

\begin{tabular}{lcc}
\hline \multicolumn{1}{c}{ Criteria } & $\begin{array}{c}\text { Normalized } \\
\text { Weights }\end{array}$ & Rank \\
\hline $\mathrm{C}_{1}$ : Service & 0.058 & 6 \\
$\mathrm{C}_{2}$ : Product Quality & 0.096 & 5 \\
$\mathrm{C}_{3}$ : Price & 0.189 & 2 \\
$\mathrm{C}_{4}$ : Financial Status & 0.047 & 7 \\
$\mathrm{C}_{5}$ : Product Variety & 0.131 & 3 \\
$\mathrm{C}_{6}$ : Capacity & 0.110 & 4 \\
$\mathrm{C}_{7}$ : Regulatory Compliance & 0.369 & 1 \\
\hline
\end{tabular}

The top three most important criteria for evaluation of suppliers are $\mathrm{C}_{7}, \mathrm{C}_{2}$ and $\mathrm{C}_{5}$ as they have the highest values of normalized weight with $0.369,0.189$ and 0.131 , respectively (Table 2 ). This is followed by criteria, $\mathrm{C}_{6}(0.110), \mathrm{C}_{2}(0.096)$ and $\mathrm{C}_{1}(0.058)$. The least important criterion is $\mathrm{C}_{4}$ which has the lowest value of 0.047. Based on the table above, $\mathrm{C}_{7}$ is the major factor in the selection of suppliers. This makes the Regulatory Compliance as the new criterion for the supplier selection process for XYZ Pharmaceutical Manufacturing company.

Table 3. Comparison Ranking between Fuzzy AHP and Fuzzy VIKOR

\begin{tabular}{cccccc}
\hline Alternatives & $\begin{array}{c}\text { Rank by } \\
\text { Decision makers }\end{array}$ & $\begin{array}{c}\text { Fuzzy AHP } \\
(\text { Score })\end{array}$ & Ranking & $\begin{array}{c}\text { Fuzzy } \\
\text { VIKOR } \\
\left(\mathrm{Q}_{\mathrm{i}}\right)\end{array}$ & Ranking \\
\hline $\mathrm{A}_{1}$ & 4 & 0.152 & 3 & 0.492 & 4 \\
$\mathrm{~A}_{2}$ & 7 & 0.089 & 5 & 0.810 & 6 \\
$\mathrm{~A}_{3}$ & 2 & 0.215 & 2 & 0.162 & 2 \\
$\mathrm{~A}_{4}$ & 6 & 0.041 & 8 & 1.000 & 8 \\
$\mathrm{~A}_{5}$ & 1 & 0.245 & 1 & 0.000 & 1 \\
$\mathrm{~A}_{6}$ & 8 & 0.060 & 7 & 0.914 & 7 \\
$\mathrm{~A}_{7}$ & 3 & 0.119 & 4 & 0.431 & 3 \\
$\mathrm{~A}_{8}$ & 5 & 0.079 & 6 & 0.744 & 5 \\
\hline Spearman's Rank & & \multicolumn{5}{c}{0.929} \\
\hline
\end{tabular}

Before applying Spearman's rank correlation coefficient, interviews were conducted with two decision makers for them to provide insight on the performance of the suppliers of the company. Based on the observation of the two decision makers, they had randomly ranked the suppliers from most important to least important accordingly and it was found that the top three most important suppliers were $\mathrm{A}_{5}, \mathrm{~A}_{3}$ and $\mathrm{A}_{7}$ followed by $\mathrm{A}_{1}, \mathrm{~A}_{8}, \mathrm{~A}_{4}$ and $\mathrm{A}_{2}$. The least important supplier was $\mathrm{A}_{6}$. After applying the Spearman's rank correlation coefficient, it shows that Spearman's rank 
correlation coefficient for Fuzzy AHP and Fuzzy VIKOR is 0.869 and 0.929, respectively (Table 3 ). This indicates that the value of coefficient which is closer to one will be selected as the best method. The results show that the performance of Fuzzy VIKOR is better as compared to Fuzzy AHP since its coefficient value is higher than Fuzzy AHP.

The comparison between the ranking based on Fuzzy VIKOR and the current practice of XYZ Pharmaceutical Manufacturing company was done to ensure that the Fuzzy VIKOR is the best method. It shows that the ranks by decision makers and the rankings based on Fuzzy VIKOR are similar for alternatives $\mathrm{A}_{1}, \mathrm{~A}_{3}, \mathrm{~A}_{5}, \mathrm{~A}_{7}$ and $\mathrm{A}_{8}$ (Table 3). Meanwhile, the rank by decision makers for $A_{2}$ is 7 but the ranking based on Fuzzy VIKOR is 6. On the other hand, the rank by decision makers for $\mathrm{A}_{4}$ is 6 but the ranking based on Fuzzy VIKOR is 8. Lastly, the rank by decision makers for $A_{6}$ is 8 but the ranking based on Fuzzy VIKOR is 7 . In respect of the years of experience in supplying pharmaceuticals raw materials, even though $\mathrm{A}_{2}$ and $\mathrm{A}_{6}$ have less experience in supplying pharmaceuticals raw materials as compared to $\mathrm{A}_{4}$, they were better in respect of delivering the supplies where $A_{2}$ and $A_{6}$ can deliver more supplies in a short duration and it can facilitate the medicine manufacturing process if there is very high demand from consumers. Therefore, Fuzzy VIKOR is considered as one of the best method in pharmaceuticals raw materials supplier selection.

\section{CONCLUSION}

Selecting the right supplier is an important process since it will give a positive impact to the performance of a company. Supplier selection is a multi-criteria Decision Making (MCDM) problem as it involves evaluation of alternative suppliers based on quantitative and non-quantitative and multiple criteria. Thus, there are some methods developed for the purpose of selection of supplier. In this study, Fuzzy AHP and Fuzzy VIKOR were used. Fuzzy theory was applied in this study since it provides a proper tool to encounter the uncertainties and complexity of decision making environment which requires human judgment.

Based on the preference of a group of decision makers, the top three most important criteria to be considered in the selection of supplier are Regulatory Compliance, Price and Product Variety. Thus, it can be concluded that XYZ Pharmaceutical Manufacturing company is giving highest attention to the regulatory compliance by the supplier. The second most important criterion is the price where XYZ Pharmaceutical Manufacturing company will ensure that the price of pharmaceutical raw materials offered by the supplier is affordable. The third most important criterion is the product variety of the supplier where suppliers can supply a variety of products to meet the needs of the company. This is followed by Capacity, Product Quality and Services. Out of the seven criteria, the least important criterion is Financial Status.

Overall the results of using the two methods, namely Fuzzy AHP and Fuzzy VIKOR show that there is slight difference in the ranking of supplier. According to the two decision makers from the Supply Chain Management Department, Fuzzy VIKOR approach is recognized as the most suitable method in selecting the best pharmaceutical raw materials supplier for XYZ Pharmaceutical Manufacturing company. Therefore, it is proven that Fuzzy VIKOR is an effective tool for supplier selection for the company since it is comprehensive and easy to understand.

\section{ACKNOWLEDGMENTS}


The author wishes to thank all experts for their valuable information and assistance in conducting the study.

\section{REFERENCES}

[1] Hsu, B. M., Chiang, C. Y., \& Shu, M. H. (2010). Expert Systems with Applications, 37(9), 6192-6200.

[2] Oliver, R. L. (2014). Abingdon, UK: Routledge.

[3] Asadabadi, M. (2014). International Journal of Industrial Engineering Computations, 5(4), 543-560.

[4] Christopher, M., Payne, A., \& Ballantyne, D. (2013). Butterworth-Heinemann: Oxford.

[5] Vovchenko, G. N., Holina, G. M., Orobinskiy, S. A., \& Sichev, A. R. (2017). European Research Studies Journal, 20(1), 350-368.

[6] Khorasani, O., \& Bafruei, M. K. (2011). International Journal of Academic Research, 3(1).

[7] Parameshwaran, R., Kumar, S. P., \& Saravanakumar, K. (2015). Applied Soft Computing, 26, 31-41.

[8] Enyinda, C.I., Emika, D. (2010). Proceedings of ASBBS, Los Vegas, February 2010, Vol.17, No.1, pp.77-91

[9] Asamoah, D., Annan, J., \& Nyarko, S. (2012). International Journal of Business and Management, 7(10), 49.

[10] Aguezzoul, A. (2014). Omega, 49, 69-78

[11] Beikkhakhian, Y., Javanmardi, M., Karbasian, M., \& Khayambashi, B. (2015). Expert Systems with Applications, 42(15), 6224-6236.

[12] Ayhan, M. B. (2013). arXiv preprint arXiv:1311.2886.

[13] Liao, H., \& Xu, Z. (2013). Fuzzy Optimization and Decision Making, 12(4), 373-392. 